\title{
New complexes of liquid crystal discotic triphenylenes: induction of the double gyroid phase
}

\author{
O.A. Otmakhova a, A.A Piryazev b,c, G.N. Bondarenko a, G.A. Shandryuk a, A.V. Maryasevskaya \\ b,c, A.S. Merekalov a, D.A. Ivanov *b,c,d, R.V. Talroze*a
}

Electron donor-acceptor liquid crystals have been attracting considerable attention due to possible applications in optoelectronics and photonics. The creation of such charge transfer complexes is a powerful and flexible instrument for modifying the structures and properties compared to those of the initial components. In the present work, such an approach is exemplified on new complexes formed via non-covalent interactions of triphenylene discotics, namely, 2,3,6,7,10,11 - hexakis(pentyloxy) triphenylene (H5T) and 2-(acryloyloxypropyloxy)3,6,7,10,11- pentapentyloxtriphenylene (TPh-3A), with an electron acceptor, $\beta$ - (2,4,7-trinitro-9fluorenylideneaminooxy) propionic acid (TNF-carb).

The structure of thin supported films of H5T, TPh-3A and their blends with TNF-carb was investigated by grazing-incidence wide-angle X-ray scattering using a synchrotron source. At room temperature, the pristine discotics crystallize in orthorhombic unit cells whereas the selfassembly of H5T and TPh-3A with TNF-carb results in a double gyroid and hexagonal phases, respectively. Formation of the double gyroid phase with the lattice parameter of $36.5 \AA$ is driven by phase separation between the aromatic and alkyl regions of the system. It is supposed that the TNF-carb molecules of the complex are positioned in the nodes of the structure while the H5T molecules are located in the struts adjoining the nodes via triple junctions. For the hexagonal crystal of the TPh-3A /TNF-carb complex, the acceptor molecules are likely located in the intersticies between the neighboring supramolecular columns of $\mathrm{TPh}-3 \mathrm{~A}$. The molecular structures of the blends were also explored by means of FTIR spectroscopy. A detailed FTIR spectra analysis illustrates fine changes in intermolecular bonds. For example, the initially dimerized acceptor molecules totally disappear in the complex structures whereas in $\mathrm{TPh}$ 3A/TNF-carb additional H-bonds between the carboxylate group in TNF-carb and the ester group of TPh-3A form. The experimental data allows putting forward possible molecular models of the complex structures.

\section{Introduction}

Discotic liquid crystals (discotics) characterized by 1D photoconductivity are of special interest for photovoltaic and other electronic applications [1]. Such properties are caused by particular columnar packing of disc-like molecules, which are prone to $\pi-\pi$ interactions between their aromatic cores [2]. In some instances, discotic molecules form thermotropic cubic bicontinous phases, which may act as alignment-free $3 \mathrm{D} \pi$ - electronic semiconductors [3]. To modify the conductivity of discotics one can add electron acceptors to form charge transfer (CT) complexes with electron-donor discotic molecules [4]. Wöhrle et al [5] discuss in detail the band-gap structure of the systems based on discotic liquid crystals as well as conditions influencing the mobility of charge carriers.

The high mobility and relatively simple processing of discotic liquid crystals may help developing these systems as an alternative to conventional semiconductors. Kaafarani [1] specifically mentions possible applications of discotic liquid crystals for organic electronic devices. The priorities of selforganized columnar systems with the $\pi-\pi$ stacking and donoracceptor complexes with 2,4,7-trinitro-9-fluorenone (TNF) are discussed as well. Bin $\mathrm{Mu}$ with coauthors [6] focus on columnar LC materials displaying both high electrical conductivity 
and strong luminescence for the cases when hydrogen bonds additionally stabilize CT complexes. TNF is

known to have an almost planar conformation and to

crystallize into a monoclinic structure [7]. It has exceptional spectroscopic and photochemical properties [8,9]. Haverkate et. al [10] used a discotic molecule, 2,3,6,7,10,11-

hexakis(hexyloxy)triphenylene (H6T), in a blend with TNF. By means of the NMR and Raman spectroscopy the authors found evidence for the ground-state electron transfer from H6T core to TNF although the estimated amount of charge involved is pretty low (0.06 electron). Different intermolecular electronic transitions comprise the excited CT-band of H6T/TNF complex.

The lowest excited state is a $\pi-\pi *$ type of transition from the HAT6 HOMO on the aromatic core to the LUMO of TNF. Thus, the control over electronic properties in such materials may be achieved via the complex formation as a powerful and versatile tool allowing tuning the energy levels of the donor and acceptor while changing the overall supramolecular structure. Previous reports allow comprehending the role of the chemical structure in the discotic/TNF complex formation and its packing in a LC phase. Indeed, in publications by the Ringsdorf's and Wendorf's groups the authors consider that the TNF acceptor molecule is incorporated into the columns formed by discotics being sandwiched between the donor molecules [11]. On the other hand, Kruglova et al. [12] and Haverkate et al. [13] put forward a structure with TNF molecules located outside the columns in the aliphatic tails regions. Moreover, in the framework of the model proposed in [13] the TNF molecules are aligned along the long columnar axes. Such a difference of the models of the systems even in the case of the same acceptor, i.e. the TNF molecule, complexed with very similar discotic liquid crystals such as H6T and 2,3,6,7,10,11hexakis(pentyloxy)-triphenylene (H5T) raises the issue about the role of different chemical structures and bonds between the components on the structure of the complex. The main goal of the current paper is to analyse the complex formation involving different symmetrical and nonsymmetrical electron-donor discotic molecules and a new electron acceptor. In the present work, we put the focus on the structure of the complexes and the constitutive complex components and on the analysis of the types of bonds responsible for the complex formation and stability. For the purpose of the study, we selected two triphenylene-containing molecules, namely, well-known H5T as a symmetrical molecule and an acrylic monomer 2(acryloyloxypropyloxy)-3,6,7,10,11- pentapentyloxy-tripheny-lene (TPh-3A) as a nonsymmetrical one.
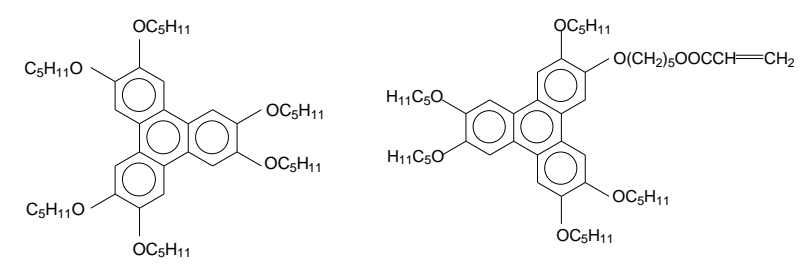

H5T

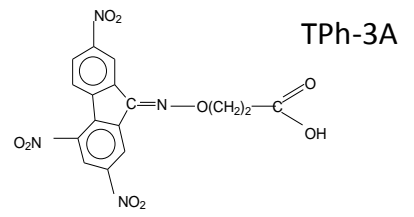

TNF-carb

Figure 1. Structures of HAT5, TPh-3A and TNF-carb. 
present study assuming that the difference in their structure may affect the structure of the complex as a whole. The insertion of the functional groups in the discotic molecule may provide additional bonding between the complex components.

The systems under study are prepared by mixing discotic triphenylene-containing molecules having different substituents with the electron acceptor, $\beta$ - (2,4,7- trinitro-9- fluorenylideneimino-oxy)propionic acid (TNF-carb). With the analysis of the structure and electronic characteristics obtained from the quantum chemical calculations given in [14] we have shown that a condensed aromatic system with three nitro groups can be a highly effective electron acceptor with a strong propensity to form intermolecular $\pi-\pi$ stacking interactions. Moreover, these systems are capable of forming $\mathrm{H}$-bonded cyclic dimers. TNF-carb may be bonded to four donor molecules such as H5T or TPh-3A due to $\pi-\pi$ interactions and hydrogen bonding (H-bond). Therefore, we focus the present research on systems with stoichiometry 4:1, i.e. containing four discotic molecules per one TNF-carb. The interest in such systems is also related to the fact that the 2- (acryloyloxypropyloxy) group in the discotic molecule will allow further polymerizing the complex.

\section{Results and discussion}

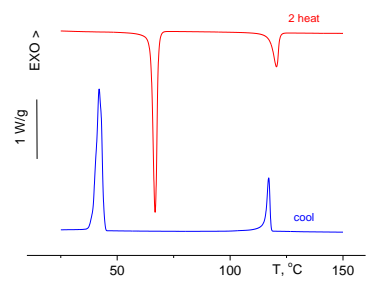

a

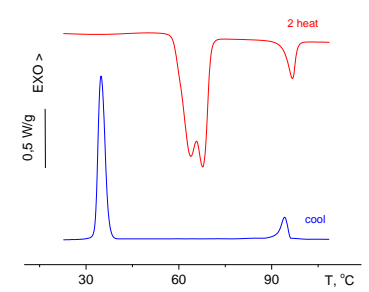

b

Figure 2. DSC curves of H5T (a) and TPh-3A (b) recorded during heating and cooling at $10 \mathrm{deg} / \mathrm{min}$.

Structure of the pristine discotics and their blends with TNF-carb The DSC curves of H5T (a) and TPh-3A (b) are shown in Figure 2.
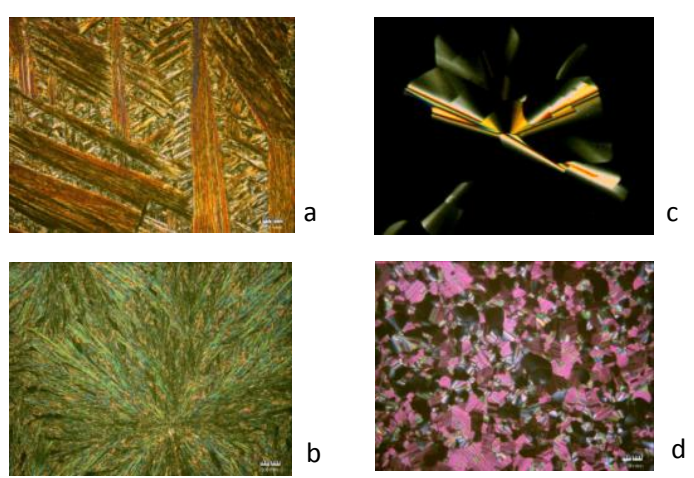

Figure 3. POM images of H5T at RT (a) and $88.4 \circ \mathrm{C}$ (c) and TPh-3A at RT (b) and $80 \circ \mathrm{C}(\mathrm{d})$.
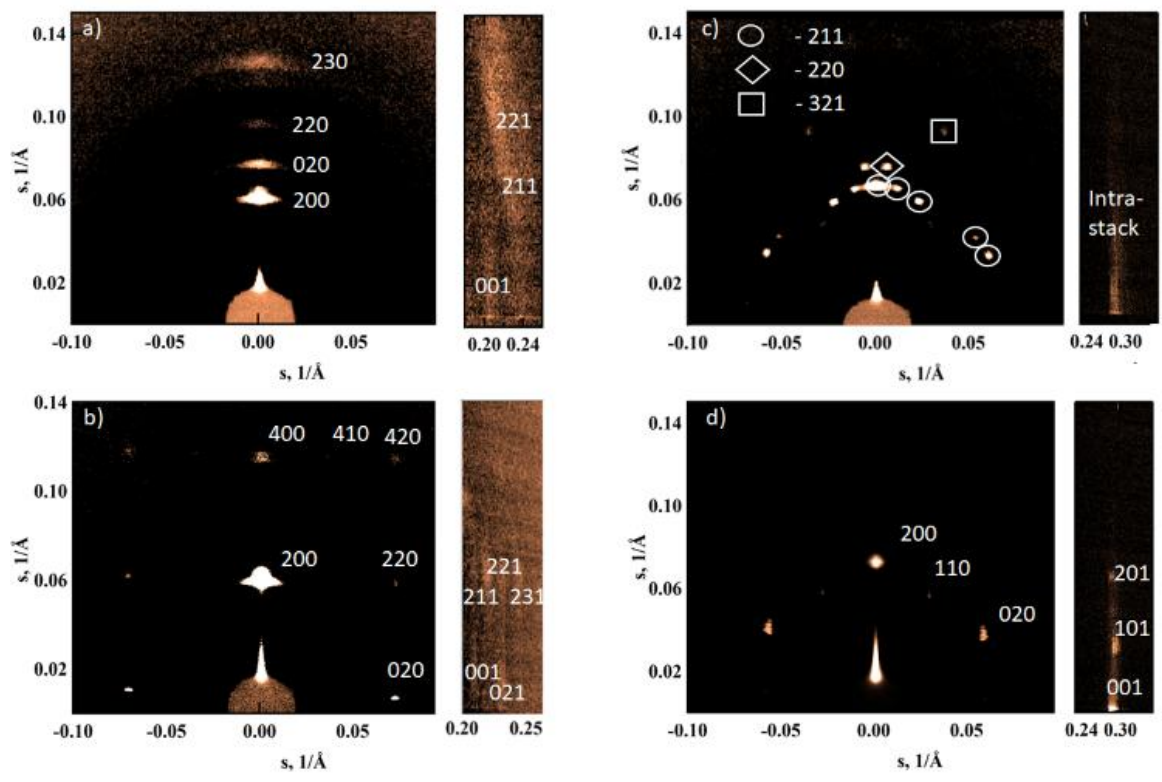
Figure 4. Room-temperature 2D GIWAXS patterns recorded on thin films of H5T (a), TPh-3A (b), H5T/TNF-carb (4:1) (c), and TPh-3A/TNF-carb (4:1) (d)

Both curves exhibit two peaks on heating and cooling. The first melting peaks under heating at 65 for H5T and 55 oC for TPh- 3A are characterized by relatively high enthalpies of 43.4 and $59.1 \mathrm{~J} / \mathrm{g}$, respectively, which serve as indications of the crystalline structures of the pristine discotics. The polarized optical microscopy (POM) data support the idea about the crystalline state of discotics at room temperature. As it is shown in Figure 3 the crystals of both discotic compounds have herring-like (a) and spherulitic optical textures (b). They melt with formation of focal conic and mosaic textures (Figure 3c,d) pertinent to liquid crystalline phases. The transitions to the isotropic phase occur at 117.5 and $93.4 \mathrm{o}$ C for H5T and TPh-3A, respectively (Figure 2). The attempts to solve the crystal structure of hexakis (alkoxytriphenylens) were previously done by M. Cotrait et al. [15] but due to several reasons they remained unsuccessful. Subsequently, in the work by T. Wang and co-authors [16], the crystal structure of H5T was indexed to an orthorhombic cell with a P2212 space group having the following cell parameters: $a=36.73$ $\AA, b=27.99 \AA$ and $c=4.91 \AA$. According to the report, the molecules in the unit cell are organized in a herring-bone type arrangement where the aromatic cores of the molecules are inclined by 48。 with respect to the ab-plane of the lattice.

In the present work, we use a synchrotron source to explore the supramolecular structures of H5T, TPh-3A and their complexes with TNF-carb employing X-ray scattering in wide angles in grazing-incidence geometry (GIWAXS). As can be seen from Figure 4, the 2D X-ray patterns recorded on thin films of the studied compounds exhibit crystalline structures (Figure 4a,b). Indeed, the GIWAXS data shows crystalline reflections with mixed $h, k$ and I Miller indices testifying that the samples form 3D crystals (Table 1). This conclusion from GIWAXS is confirmed by the thermal analysis and POM.

Table 1. Experimental and calculated diffraction peaks positions at room temperature

\begin{tabular}{|c|c|c|c|c|c|c|c|}
\hline $\begin{array}{c}\text { H5T } \\
\text { hkl/d- } \\
\text { spacing, } \AA\end{array}$ & $\begin{array}{c}\text { H5T } \\
\text { Fit, } \AA\end{array}$ & $\begin{array}{c}\text { H5T/TNF- } \\
\text { carb } \\
\text { hkl/d- } \\
\text { spacing, } \AA\end{array}$ & $\begin{array}{l}\text { H5T/TNF- } \\
\text { carb } \\
\text { fit, } \AA\end{array}$ & $\begin{array}{c}\text { TPh-3A } \\
\text { hkl/d- } \\
\text { spacing, } \AA\end{array}$ & $\begin{array}{c}\text { TPh-3A, fit, } \\
\AA\end{array}$ & $\begin{array}{c}\text { TPh-3A/TNF- } \\
\text { carb } \\
\text { hkl/d- } \\
\text { spacing, } \AA \\
\end{array}$ & $\begin{array}{c}\text { TPh-3A/TNF- } \\
\text { carb fit, } \AA\end{array}$ \\
\hline $200 /$ & & $211 /$ & & $200 /$ & & $110 /$ & \\
\hline 16.4 & 16.4 & 14.8 & 14.9 & 16.8 & 17.0 & 15.6 & 15.5 \\
\hline $020 /$ & & $220 /$ & & $400 /$ & & $200 /$ & \\
\hline 13.2 & 13.3 & 12.6 & 12.9 & 8.7 & 8.6 & 13.7 & 13.7 \\
\hline $220 /$ & & $321 /$ & & $020 /$ & & $020 /$ & \\
\hline $10.3 /$ & 10.3 & 9.6 & 9.8 & 13.5 & 13.6 & 13.9 & 13.7 \\
\hline $230 /$ & & Intra-stack/ & & $220 /$ & & $001 /$ & \\
\hline 8.0 & 7.9 & 3.5 & & 10.7 & 10.7 & 3.5 & 3.5 \\
\hline 001/ & & & & $420 /$ & & $101 /$ & \\
\hline 4.8 & 4.7 & & & 7.4 & 7.3 & 3.4 & 3.4 \\
\hline \multirow{12}{*}{$\begin{array}{c}211,221 / \\
4.5 \\
\end{array}$} & & & & $210 /$ & & 201/ & \\
\hline & 4.6 & & & 14.4 & 14.4 & 3.4 & 3.4 \\
\hline & & & & $\begin{array}{c}410 / \\
8.3\end{array}$ & 8.2 & & \\
\hline & & & & $\begin{array}{c}230 / \\
8.2\end{array}$ & 8.2 & & \\
\hline & & & & $\begin{array}{l}610 \\
5.7\end{array}$ & 5.6 & & \\
\hline & & & & 001/ & & & \\
\hline & & & & 4.5 & 4.5 & & \\
\hline & & & & $\begin{array}{c}021 / \\
4.2\end{array}$ & 4.2 & & \\
\hline & & & & $\begin{array}{c}001 / \\
4.6\end{array}$ & 4.6 & & \\
\hline & & & & $\begin{array}{c}211 / \\
4.4\end{array}$ & 4.4 & & \\
\hline & & & & $\begin{array}{c}221 / \\
4.2\end{array}$ & 4.2 & & \\
\hline & & & & $\begin{array}{c}231 / \\
4.0\end{array}$ & 4.0 & & \\
\hline
\end{tabular}


Moreover, the diffractograms display pronounced textures. Thus, on the GIWAXS pattern of H5T, the hk0 diffraction peaks display preferential orientation on the meridian of the pattern, which corresponds to the planar orientation of the directspace $c$-vector of the lattice. Although the relative intensities of the peaks qualitatively match the ones reported in [17], their dspacings are slightly smaller than the ones in the cited report. In Table 1, we present the experimental $d$-spacings, as well as their fits to the different structural models. It can be seen that the adjustment of the peaks of H5T to an orthorhombic lattice provides a good match of the experimental and fitted values. The extracted lattice parameters are $a=32.8 \AA, b=26.5 \AA, c=4.7 \AA$, which correspond to the density of the crystal phase of $1.21 \mathrm{~g} / \mathrm{ml}$ for 4 molecules per unit cell. The extracted lattice parameters are somewhat smaller than the ones found in [16], which might be due to a different sample preparation method.

The studied film of TPh-3A also reveals an orthorhombic unit cell with the following parameters: $a=34.1 \AA$, $b=27.3 \AA, c=4.5 \AA$. As compared to the unit cell of H5T, the relative increase in the lateral lattice parameters may reflect the additional space required to pack the modified side chain of TPh-3A containing a double bond. Interestingly, the film texture of TPh-3A is clearly different from that of H5T. First of all, it is much better oriented because it displays point-like reflexes instead of arcs of a circle. Secondly, the texture of the film is likely biaxial instead of a simple planar texture of H5T that might stem from crystallization of the parent high-temperature hexagonal columnar mesophase $[18,19]$, with the columns being oriented in the plane of the film. In the case of TPh-3A, the $c$ parameter of the unit cell is also lying in the plane of the film. The sample probably exhibits large single-crystalline domains with a size comparable or larger than the X-ray beam crosssection. Blending of H5T and TPh-3A with TNF-carb dramatically modifies their structures. Indeed, the corresponding diffraction patterns (cf. panels $\mathrm{c}$ and d of Figure 4) show the presence of a gyroid and hexagonal phases, respectively.

The assignment of the observed gyroid phase to a double gyroid is based on the selection rules summarized in a recent work [19]. The double gyroid phase, which is a bicontinuous cubic phase, displays a typical orientation in thin films in which the intense 211 reflection is oriented along the meridian of the pattern [20]. The a-parameter of a cubic lattice of this double gyroid phase is $36.5 \AA$. The change of the high-temperature liquid-crystalline hexagonal columnar phase of pure H5T to a double gyroid structure upon complexation with TNF-carb is likely to be connected to modification of the curvature of the interphase between the aromatic and alkyl regions of the systems as discussed in [21, 22]. The extent of the interphase curvature in this case is believed to be intermediate between that of a hexagonal columnar phase and a flat smectic phase. This change is clearly caused by modification of the geometry of the elementary building block, the molecular details of which will be analysed further with the use of FTIRspectroscopy.

As for the optical texture presented in Figure 3a, it is focal-conic and differs from the expected isotropic optical texture known for the gyroid phases. However, as it is seen in Figure $4 \mathrm{c}$ the diffraction pattern exhibits the characteristic intra-columnar peak typical of the ordered high-temperature hexagonal phase of H5T. We speculate that the system possibly contains remnants of the supramolecular columns, which might be indicative of a different stoichiometry of the blend in the double gyroid phase. For the case of the TPh- 3A/TNF-carb complex, one observes a GIWAXS pattern that can be indexed to a hexagonal crystal with the following parameters: $a=b=47.6 \AA, c=3.5 \AA$, alpha=beta=90。, gamma=120。. The $c$-parameter is lying in the plane of the film, which makes the film texture similar to the one observed for
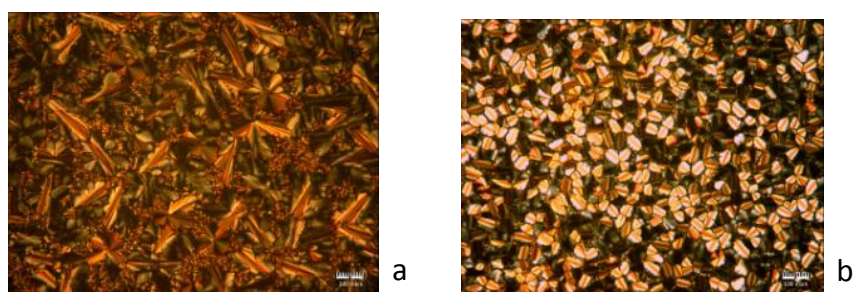

Figure 5. POM images of H5T/TNF carb (a) and TPh-3A/TNF carb (b) blends at RT.

the pure H5T and TPh-3A compounds. The decreased intermolecular stacking distance in the complex can be accounted for by a change in the molecular tilt in the columns to the almost flat-on in the hexagonal phase. The optical textures of 4:1 blends are shown in Figure 5. The texture of TPh-3A/TNF-carb can be identified as mosaic with rectilinear defects.

Taking into account the complex formation between the two components it is important to understand what type of noncovalent bonds is responsible for the complex stability. To tackle this issue, we have carried out FTIR measurements described in the following section.

\section{Molecular structure of the blends}

The comparison of FTIR spectra of H5T, TPh-3A, TNF-carb and the blends of 4:1 compositions (Table 2) shows that the FTIR spectrum of the blends is not an additive composition of the spectra of both components (Figure S1). Many spectral bands change both the relative intensities and positions of maxima. It proves the fact that the blend is not a simple mechanical mixture but a complex in which components are interacting.

Table 2. Comparison of the major absorption bands in IR spectra of initial components and their blends of 4:1 (H5T/TNF-carb and TPh-3A/TNF-carb)

\begin{tabular}{|l|c|c|c|c|c|c|}
\hline \multirow{2}{*}{$\begin{array}{l}\text { Absorption } \\
\text { range, } \mathrm{cm}^{-1}\end{array}$} & Assignment & \multicolumn{5}{|c|}{ Absorption bands (cm ${ }^{-1}$ ) } \\
\cline { 3 - 6 } & & TNF-carb & H5T & TPh-3A & H5T/TNF-carb & $\begin{array}{c}\text { TPh-3A/ TNF- } \\
\text { carb }\end{array}$ \\
\hline
\end{tabular}




\begin{tabular}{|c|c|c|c|c|c|c|}
\hline $2800-2400$ & $\mathrm{C}=\mathrm{O} \ldots \mathrm{HO}$ & $2762,2662,2553$ & - & - & $\begin{array}{c}2737,2698 \\
2632,2593 \\
2530\end{array}$ & $\begin{array}{c}2739,2675 \\
2638,2600 \\
2528\end{array}$ \\
\hline $1800-1700$ & $\begin{array}{l}\mathrm{v}_{\mathrm{C}=0} \text { in } \\
\mathrm{C}(\mathrm{O}) \mathrm{OH} \\
\mathrm{v}_{\mathrm{C}=\mathrm{O}} \text { in } \\
\mathrm{C}(\mathrm{O}) \mathrm{OR}\end{array}$ & $\begin{array}{c}1703 \\
-\end{array}$ & - & $\begin{array}{c}- \\
1724\end{array}$ & $\begin{array}{c}1710 \\
-\end{array}$ & $\begin{array}{l}1710 \\
1734\end{array}$ \\
\hline $1620-1500$ & $\begin{array}{c}\mathrm{V}_{\mathrm{C}=\mathrm{C}} \\
\mathrm{V}_{\mathrm{C}}=\mathrm{C}(\mathrm{Ph})\end{array}$ & $\begin{array}{c}1612 \\
1594,1528\left(\mathrm{NO}_{2}\right)\end{array}$ & $\begin{array}{c}- \\
1617,1518\end{array}$ & $\begin{array}{c}- \\
1617,1517\end{array}$ & $\begin{array}{l}1612,1594, \\
1515\left(\mathrm{NO}_{2}\right)^{*}\end{array}$ & $\begin{array}{c}1612 \\
1615,1600 \\
1513\left(\mathrm{NO}_{2}\right)\end{array}$ \\
\hline $1530-1320$ & $\mathrm{~V}_{\mathrm{N}=\mathrm{O}}$ in $\mathrm{NO}_{2}$ & 1528,1346 & - & - & 1515,1337 & 1513,1340 \\
\hline $1500-1350$ & $\begin{array}{c}\delta_{\mathrm{CCH}}\left(\mathrm{CH}_{2},\right. \\
\left.\mathrm{CH}_{3}\right)\end{array}$ & $1460,1435,1408$ & $\begin{array}{c}1468,1439 \\
1388\end{array}$ & $\begin{array}{c}1470,1443, \\
1388\end{array}$ & $\begin{array}{c}1466,1435 \\
1386\end{array}$ & $\begin{array}{c}1465,1434 \\
1385\end{array}$ \\
\hline $1240-950$ & $\mathrm{~V}, \delta_{\mathrm{C}-\mathrm{O}-\mathrm{C}, \mathrm{C}-\mathrm{OH}}$ & 1016 & $\begin{array}{c}1262,1175 \\
1055\end{array}$ & $\begin{array}{c}1265,1175 \\
1055\end{array}$ & $\begin{array}{l}1266,1179, \\
1074,1030\end{array}$ & $\begin{array}{l}1259,1169 \\
1072,1028\end{array}$ \\
\hline $910-700$ & $\delta_{\mathrm{CCH}(\mathrm{Ph})}$ & $908,846,794,737$ & 835 & 838 & $\begin{array}{c}898,840,793 \\
766,727\end{array}$ & $\begin{array}{c}900,838,794 \\
764,729\end{array}$ \\
\hline
\end{tabular}

The analysis of Table 2 data shows that the major changes in the blends spectra proceed in the absorption range of carboxyl group. The stretching band at $1703 \mathrm{CM}-1$ related with $\mathrm{C}=0$ bond in carboxylic group of TNF-carb shifts down to $1710 \mathrm{~cm}-1$ in the spectra of H5T/TNF-carb and TPh-3A/TNF-carb blends. On one hand, this shift towards shorter wavelengths serves as a sign of the increase in the electron density on that bond. On the other hand, $1703 \mathrm{~cm}-1$ band $(\mathrm{vc}=\mathrm{O}$ in $\mathrm{C}(\mathrm{O}) \mathrm{OH})$ in TNF-carb spectrum is shifted in the longwave region because these bands in carbonic acids spectra are usually located above $1710 \mathrm{~cm}-1$. Most likely, this means that the carboxylic groups in the solid TNF-carb form hydrogen bonds (H-bonds) as shown in Scheme 1.

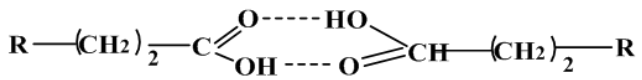

Scheme 1. Association of carboxylic groups in TNF-carb molecules in a dimer

In such a dimer the delocalization of electron density
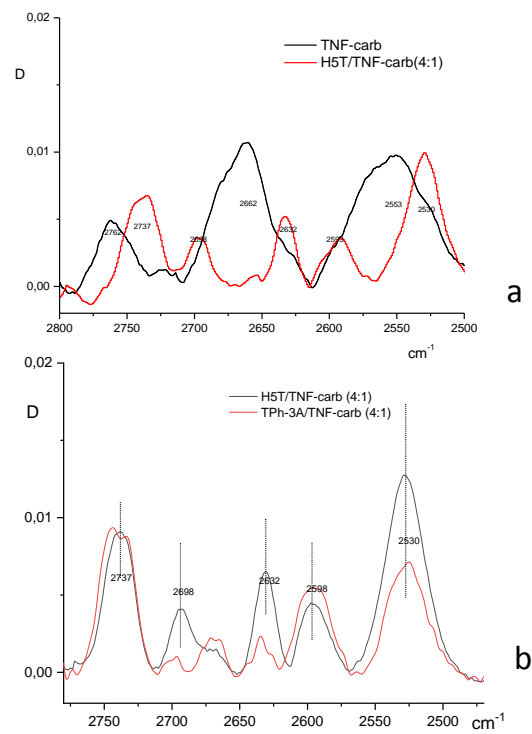

Figure 6. Comparison of IR spectra a: TNF-carb and H5T/TNF-carb and b: (4:1) blends of H5T/TNF-carb and TPh-3A/TNF-carb. 
results in the shift of the stretching band $\mathrm{v} c=\mathrm{O}$ in $\mathrm{C}(\mathrm{O}) \mathrm{OH}$ towards long wavelength down to $1703 \mathrm{~cm}-1$. The associates of such a kind usually show several weak bands in $2800-2400 \mathrm{~cm}-1$ wavelength range, and the number and intensities of those bands depend on the local symmetry of the associate [23]. The dimer associate shown in Scheme 1 has local symmetry high enough (not lower, than C2v). In accordance with the theory of oscillation spectra [23] in spectra of systems of high symmetry the frequency degeneracy is manifested. It corresponds to the appearance of frequencies with equal energy of oscillation and wavelength. The latter results in the decrease of the number of absorption bands. In the case of TNF-carb the associates of such a kind have three broad bands between 2800 and $2400 \mathrm{~cm} 1$ (Figure 6a, Table 2).

The bands are not present in the spectrum of H5T/TNF-carb (4:1) but one can see instead five new bands (Figure 6a). It serves as indication of the disappearance of the symmetrical dimer and proves the formation of new less symmetrical associate: Scheme 2 shows the possible structure based on carboxylic group of TNF and electronegative oxygen atom in the ether group of H5T.<smiles>[R]CCCCCC(=O)OOc1ccccc1</smiles>

Scheme 2. Association of the carboxylic group in TNF-carb with the ether group in H5T.

The local symmetry of such associate (Scheme 2) is much lower (Cs) than that in TNF-carb dimer (Scheme 1). It is accompanied by the removing frequency degeneracy manifested by the increase in the number of bands up to 5 in IR spectra of the blends (Figure $6 \mathrm{~b}$ and Table 2). In addition the delocalization of the electron density in less symmetrical dimer (Scheme 2 ) is lower than that in the symmetrical one (Scheme 1) and vc=o band is shifted down to $1710 \mathrm{~cm}-1$. At the same time absorption bands related with C-O-C bonds and angles in 1210-1160 cm-1 range are shifted in the spectrum of the blend in comparison with that of H5T and TPh-3A (Table 2).

As for systems, containing TPh-3A there is a difference in the spectral range of $\mathrm{C}=\mathrm{O}$ stretching vibration. There are two bands at 1734 and $1710 \mathrm{~cm}-1$, which do not coincide with similar bands in the initial components at $1703 \mathrm{~cm}-1$ (TNF-carb) and $1724 \mathrm{~cm}-1$ (TPh-3A) (Table 2). It means that every band is shifted to a shorter wavelength. One also observes changes in the range of carboxylate associates (2500-2800 cm-1): the bands related with TNF-carb dimer disappear and five new though weak broad peaks appear (Figure 6b) that coincide with the bands of the similar blend H5T/TNF-carb. One can suppose that in that blend two types of interactions exist as well but in addition, the carboxylate group in TNF-carb forms a $\mathrm{H}$-bond with the ester group of TPh-3A (Scheme 3).<smiles>[R]CCCCCCC(=O)O</smiles>

Scheme 3. Association of carboxylic group of TNF-carb with the TPh-3A acrylate group.

Thus, one can state that hydrogen bonds are definitely responsible for the formation of blends. However, we also observe the strongest changes in the blends spectra in comparison with those of individual components in the range of nitro group absorption (1530 - $1320 \mathrm{~cm}-1)$ as well as in the absorption wavelength range $910-700 \mathrm{~cm}-1$, which is related with out-of-plane oscillation deformation of $\mathrm{CCH}$ group in aromatic cores (Table 2). An additional stabilization of the blend components is possible due to donor-acceptor interaction between the electron deficient carbon atoms in aromatic core of TNF-carb located in orthoposition related to nitro groups and electron donor ether groups in H5T or TPh- 3A. The interaction of such type has to induce slight changes of valence angles in both nitro groups and the neighbouring $\mathrm{C}-\mathrm{CH}$ angles within TNF-carb structure and valence angles (Ph)CO- C(Alk) and alkyl ligand conformation in H5T or TPh-3A. The latter will lead to the shift of bands in the absorption range of nitro groups, out-of-plane deformation oscillations $\delta \mathrm{ccH}$ in TNFcarb aromatic cores as well as in the range of deformation oscillations of alkyl groups. It is well seen in the spectra of H5T/TNF-carb (or TPh-3A) (Table 2). Due to TNF-carb molecule contains three nitro groups providing donor-acceptor interactions and one carboxylic group participating in $\mathrm{H}$-bond it is easy to imagine the optimal ratio of H5T/TNF-carb (or TPh- 3A) to be 4:1.

If one compares the FTIR spectra of H5T/TNF-carb blends with different component ratios 1 - 4:1, 2 - 2:1 (Figure S2a) the absorption region of the bands from the carboxyl group and associates in these spectra looks exactly the same. The difference between the spectra of blends of different compositions lies in the fact that the intensities of the bands from nitro groups in the spectrum of the H5T/TNF- carb composition equal 2:1 decrease less noticeably in comparison with the spectrum of the 4:1 composition. In addition, two bands from nitro groups (1526 and $1344 \mathrm{~cm}-1)$ and from outof- plane C-CH vibrations of aromatic rings (850-700 cm-1) are more split than in the spectrum of 4:1 blend. In the case of TPh-3A/TNF-carb 4:1 blend the spectrum shows two bands of $\mathrm{C}=0$ groups at 1710 and $1734 \mathrm{~cm}-1$ shifted to the shorter wavelengths than those of components (Table 2). In the spectra of blends of different compositions (Figure 7) one can see one wide and splitted band in this range. It allows supposing, that blends may contain both associates and separate components creating the overlap of several bands in 


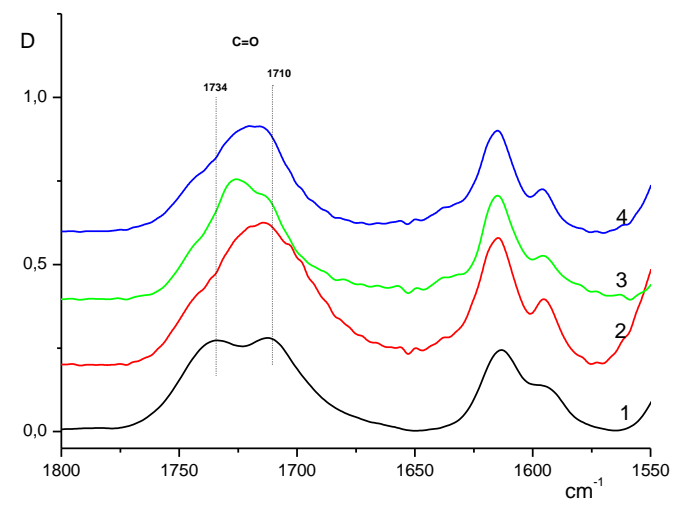

Figure 7. Comparison of IR spectra of TPh-3A/TNF-carb blends of different compositions. 1-4:1, $2-3: 2,3-1: 1,4-2: 3$

$\mathrm{C}=\mathrm{O}$ absorption region. As for $2800-2400 \mathrm{~cm}-1$ this spectral region for different compositions $3: 2,1: 1$ n 2:3 is not that informative due to very weak, non-resolved bands (Figure S2b). Thus, the analysis of FTIR spectra of H5T/TNF-carb and TPh3A/TNF-carb blends of different compositions show that between components complexes may be formed when isolated from solutions. This can only be explained by the fact that complexation in mixtures of different compositions occurs with the participation of the same functional groups, but the complexes formed in the case of 2:1 composition are less symmetric (or more diverse) than those of 4:1 composition.

\section{Models of the blend structures}

The acquired X-ray data can help us proposing molecular models of the complexes. For the H5T/TNF-carb complex, one can readily estimate the number of molecules in the unit cell. Indeed, we recall that the unit cell of the double gyroid phase contains 16 nodes and 24 struts connecting them, whereby the structure is composed of triple junctions of the struts. Since the acceptor is capable of complexing several H5T molecules it seems reasonable to suppose that the nodes are occupied by TNFcarb. Each strut then can contain an integer number of H5T molecules, which probably equals one because of the calculated density values. The distance between the nodes is given by $(\mathrm{av} 2) / 4=12.8 \AA$. This is compatible with the size of the aromatic core of H5T. Figure 8a shows schematics of the proposed molecular arrangement in the double gyroid phase overlaid on the conventional representation of the phase based on the known trigonometric equation (cf. e.g., [24]).

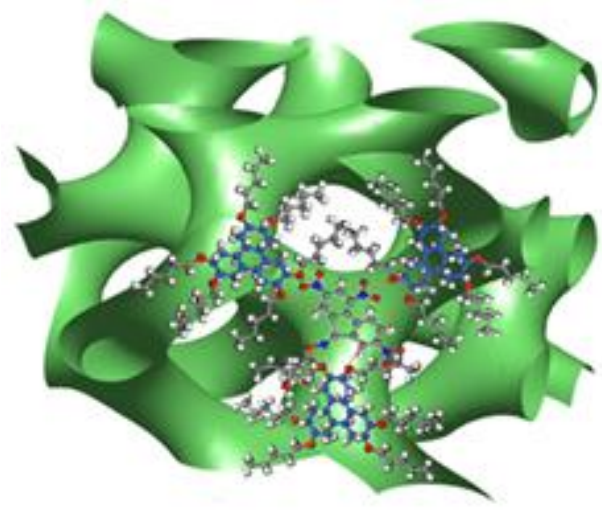

a

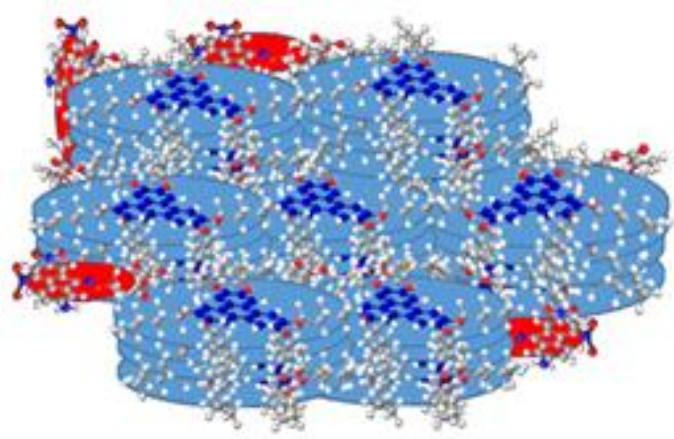

b

Figure 8. Hypothetic structures of H5T/TNF-carb (a) and TPh-3A/TNF-carb (b) at RT. For the sake of clarity, the triphenylene cores of TPh-3A are marked in dark blue. Hydrogen bonds are shown in panel (a) with red dashed lines.

The green channels in this representation correspond to the volume occupied by the aromatic molecular fragments while the rest of the unit cell is filled with the phase-segregated alkyl tails. The difference between the overall stoichiometry of the blend and that of the proposed structure can account for the birefringence of the observed optical texture, which is not isotropic as it should have been for a pure gyroid phase. We speculate that the excess of H5T can segregate out of the gyroid domains and self-assemble revealing the characteristic features of the columnar stacking typical of the bulk H5T in the corresponding diffraction pattern.

As far as the structure of the TPh-3A/TNF-carb complex is concerned, it can be thought of as a hexagonal system in which the acceptor molecules are located in the interstices between the columns as shown in Fig. 8b. One can conclude that even a small modification in the structure of H5T can result in a significant variation of the structure of its complex with TNF-carb. In 
particular, addition of a relatively small but asymmetric 2-(acryloyloxypropyloxy) group on one of the alkyl arms of H5T makes it changing the symmetry of the phase from cubic to hexagonal. Such impact of a small substituent on the final supramolecular structure can be accounted for by its H-bonding with the carboxylic group of TNF-carb.

\section{Experimental}

\section{Synthetic procedures.}

I. Synthesis of 2,3,6,7,10,11 - hexakis(pentyloxy)triphenylene

(H5T). H5T was synthesized according to the well-known process described elsewhere [25, 26].

\section{II.Synthesis of 2-(acryloyloxypropyloxy)-3,6,7,10,11- pentapentyloxytriphenylene (TPh-3A).} 1. Synthesis of a mixture of 1-hydroxy-2-pentyloxybenzene and 1,2-dipentyloxybenzene.

The synthesis was carried out according to the procedure described in [26]. $22 \mathrm{~g}$ of benzoate, $90.6 \mathrm{~g}$ of brompentane, $42.9 \mathrm{~g}$ of potassium carbonate and $110 \mathrm{ml}$ were placed in a $500 \mathrm{ml}$ round-bottom flask. ethanol. The resulting mixture was boiled for 18 hours in an inert atmosphere of argon. After that, $110 \mathrm{ml}$ of methylene chloride was added to the reaction flask, the solution was separated from the precipitate, and the precipitate was washed three times with methylene chloride. The washing solutions were combined with the basic solution and evaporated. The result was a dark brown oil weighing $30 \mathrm{~g}$. The product was distilled in vacuum. The boiling point of the product is $101-108{ }^{\circ} \mathrm{C}$ (at $0.9 * 10-3 \mathrm{~atm}$ ). Yield $85 \%$. The main paragraph text follows directly on here.

\section{Synthesis of 2-hydroxy-3,6,7,10,11-pentapentyloxytriphenylene.}

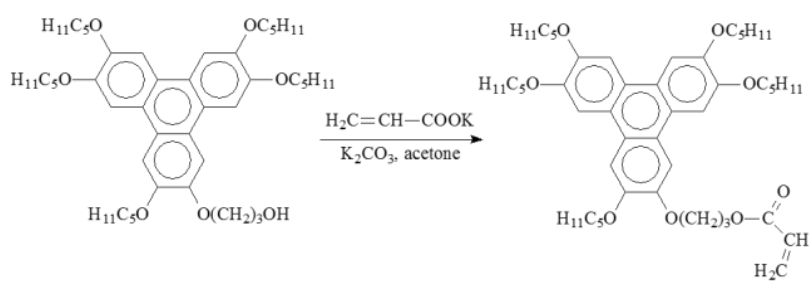

$22 \mathrm{~g}$ of benzoate were placed in a $250 \mathrm{ml}$ round bottom flask, $50 \mathrm{ml}$ of dry methylene chloride were added, and the reaction<smiles></smiles>

flask was filled with argon while stirring. Then, $13 \mathrm{~g}$ of iron trichloride and 5 drops of concentrated sulfuric acid were added to the reaction flask in three sets at intervals of 15 minutes. After 1 hour of stirring, the reaction mass turned yellow-green. After completion of the reaction (about 4 hours), the mixture was vigorously poured into chilled methanol and the solution was refrigerated. After 24 hours, the precipitate was separated on a funnel with a filter bottom, washed several times with cold methanol. The precipitate was dried in vacuum. As a result, a mixture of substances weighing $25 \mathrm{~g}$ was obtained. Based on the characteristic spots on the thin-layer chromatogram (eluent petroleum ether: methylene chloride 2:1), it was concluded that a mixture of 2,3,6,7,10,11- hexapentyloxytriphenylene and 2-hydroxypropyloxy-3,6,7,10,11-pentapentyloxy-triphenylene.

\section{Synthesis of 2-hydroxypropyloxy-3,6,7,10,11-pentapentyloxytriphenylene.}

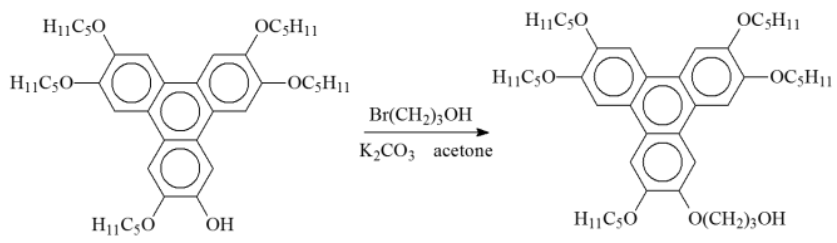

The resulting mixture of substances was placed in a $250 \mathrm{ml}$ three-necked flask and added $60 \mathrm{ml}$. acetone. Then, $8 \mathrm{~g}$ of 3bromopropanol- 1 and $7.5 \mathrm{~g}$ of potassium carbonate were introduced into the reaction flask. The flask was filled with argon. The reaction mixture was heated with stirring for 12 hours. Potassium carbonate was filtered off, washed with methylene chloride and methanol, the main and washing solutions were combined, and the solution was evaporated, as a result of which a dark violet mass was obtained. Isolation of 1-hydroxypropyloxy-2,5,6,8,9-pentapentyloxytriphenylene was carried out using a chromatographic column using silica gel 60 (63-200 microns) as an adsorbent, and ethyl acetate: petroleum ether in a ratio of $1: 4$ as an eluent (to separate 2,3,6,7,10,11-hexapentyloxytriphenylene), and then in a $1: 1$ ratio (to wash out 2hydroxypropyloxy-3,6,7,10,11- pentapentyloxytri-phenylene from the column). After evaporation of the solution, dark violet oil 
was obtained, cold methanol was added to it and put in the refrigerator for a day. Then the precipitate was filtered off and dried in vacuo. As a result, a white substance weighing $7.5 \mathrm{~g}$ was obtained. Melting point $104^{\circ} \mathrm{C}$. Yield $30.3 \%$.

\section{Synthesis of 2-(acryloyloxypropyloxy)-3,6,7,10,11- pentapentyloxy-triphenylene.}

Into a $250 \mathrm{ml}$ round bottom flask $7.5 \mathrm{~g}$ of 1-hydroxypropyloxy- 2,5,6,8,9-pentapentyloxytriphenylene, crystalline 2,6ditretbutyl-p-cresol, $10 \mathrm{ml}$, were placed in methylene chloride, $0.18 \mathrm{ml}$ ethylene carbonyl halide and $0.24 \mathrm{ml}$ triethylamine. After all the starting materials were added to the flask, another $10 \mathrm{ml}$ of methylene chloride was added. The reaction was carried out with stirring and heating for 12 hours. After 12 hours of heating, the dark blue reaction mixture was poured into well-chilled water (with pieces of ice). Next, $50 \mathrm{ml}$ was added to this mixture. methylene chloride and the whole mixture was transferred to a separatory funnel, to which dry sodium bicarbonate was added, dissolving it in the introduction layer. The organic layer was separated, and the aqueous layer was washed with methylene chloride, the basic and washing solutions were combined, the entire organic layer was washed with water three times and dried over sodium sulfate. The solution was evaporated, ethanol was added to the remaining dark purple oil and left in the refrigerator for a day. Light violet crystals were filtered off and dried in vacuo. Then, the substance was purified twice on a chromatographic column (eluent - ethyl acetate : petroleum ether 1:1). The result was a white substance weighing $3.2 \mathrm{~g}$. Yield $16 \%$. The melting point is $68.1{ }^{\circ} \mathrm{C}$, the isotropization temperature is $97.9^{\circ} \mathrm{C}$. Identification of the obtained monomer was carried out by $1 \mathrm{H} \mathrm{NMR} \mathrm{spectroscopy}\left(\mathrm{CDCl}_{3}\right)$ : $\delta(\mathrm{ppm}) 7.84+7.81(6 \mathrm{H}, \mathrm{Ar}-\mathrm{H}), 6.42\left(\mathrm{~d}, 1 \mathrm{H}, \mathrm{COCH}=\mathrm{CH}_{2}\right), 6.13\left(\mathrm{dd}, 1 \mathrm{H}, \mathrm{COCH}=\mathrm{CH}_{2}\right)$,

$5.81\left(\mathrm{~d}, 1 \mathrm{H}, \mathrm{COCH}=\mathrm{CH}_{2}\right), 4.47\left(\mathrm{t}, 2 \mathrm{H}, \mathrm{OCH}_{2}\left(\mathrm{CH}_{2}\right) 2 \mathrm{OCO}\right), 4.31\left(\mathrm{t}, 2 \mathrm{H}, \mathrm{O}\left(\mathrm{CH}_{2}\right) 2 \mathrm{CH}_{2} \mathrm{OCO}\right), 421\left(\mathrm{t}, 10 \mathrm{H}, \mathrm{OCH}_{2}\left(\mathrm{CH}_{2}\right) 3 \mathrm{CH}_{3}\right), 2.00-$ $1.86\left(\mathrm{~m}, 10 \mathrm{H}, \mathrm{OCH}_{2} \mathrm{CH}_{2}\left(\mathrm{CH}_{2}\right) 2 \mathrm{CH}_{3}\right), 2.36-2.22\left(\mathrm{~m}, 2 \mathrm{H}, \mathrm{OCH}_{2} \mathrm{CH}_{2} \mathrm{CH}_{2} \mathrm{O}\right), 1,65-1.35\left(\mathrm{~m}, 2 \mathrm{OH}, \mathrm{OCH}_{2} \mathrm{CH}_{2}\left(\mathrm{CH}_{2}\right) 2 \mathrm{CH}_{3}\right), 1.1-0.8(\mathrm{t}, 15 \mathrm{H}$, $\left.\mathrm{OCH}_{2} \mathrm{CH}_{2}\left(\mathrm{CH}_{2}\right) 2 \mathrm{CH}_{3}\right)$. The NMR results are in good coincidence with the theoretical spectrum and data reported in [26].

\section{Synthesis of 2,4,7-(Trinitro-9-fluorenylideneaminooxy)} propionic acid (TNF-carb).

The synthesis of 2,4,7-trinitro-9- fluorenylidene-aminooxy)propionic acid (TNF-carb) described

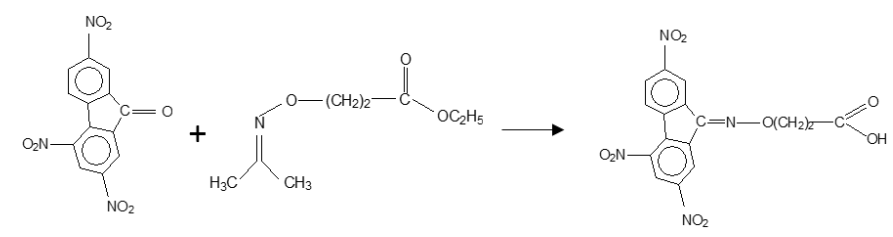

in [27] was performed according to the scheme. We mixed $10 \mathrm{~g}(25.5 \mathrm{mmol})$ of TNF (TCC, Japan) and $4.5 \mathrm{~g}(26 \mathrm{mmol})$ of the alkylated oxime in $100 \mathrm{ml}$ of acetic acid with $0.75 \mathrm{~g}(38.5 \mathrm{mmol})$ of 4-toluenesulfonic acid monohydrate as catalyst. Hydrolysis of the corresponding ester and twofold recrystallization from acetone yielded $8.5 \mathrm{~g}(85 \%)$ of the product: $\mathrm{Tm}=203 \mathrm{oC} ; \mathrm{IR}(\mathrm{KBr})$ : $\mathrm{v}=1700 \mathrm{~cm}-1(\mathrm{C}=0) .1 \mathrm{H}$ NMR $(400 \mathrm{MHz}$, acetone $-\mathrm{d} 6): \delta(\mathrm{ppm})=9.34$ and $9.11(2 \mathrm{~s} ; 1 \mathrm{H}, \mathrm{H} 3), 8.95$ and 8.88 (as, $1 \mathrm{H}, \mathrm{H} 1), 8.70$ and $8.58(2 \mathrm{~s}, 1 \mathrm{H}, \mathrm{H} 8), 8.54$ and $8.43(2 \mathrm{~d}, 1 \mathrm{H}, \mathrm{H} 6), 8.28$ and $8.18(2 \mathrm{~d}, 1 \mathrm{H}, \mathrm{H} 5), 4.90\left(\mathrm{t} ; 2 \mathrm{H}, \mathrm{N}-\mathrm{OCH}_{2}\right), 3.02(\mathrm{t} ; 2 \mathrm{H}, \mathrm{CH},-\mathrm{CO}-\mathrm{OH})$. Microanalysis: calculated C- $47.77 \%, \mathrm{H}-2.51 \%, \mathrm{~N}-13.93 \%$; found C- $47.80 \%, \mathrm{H}-2.50 \%, \mathrm{~N}-13.90 \%$.

Preparation of blends.

The complexes were obtained by mixing H5T and TPh-3A with TNF-carb in 4:1 molar proportion in THF. In addition H5T/TNFcarb were also prepared in 2:1 and TPh-3A/TNF-carb in 2:1, 3:2, 2:3 and 1:1 molar proportions for FTIR measurements. The mixtures was subsequently evaporated to dryness at room temperature. To remove any traces of solvent and to ensure the correct phase behavior, the resulting composites were heated up to the isotropization temperatures, and then cooled slowly.

\section{Characterization methods}

Film preparation. The films were prepared by spin-coating on Si substrates with the help of a spin-150 machine (APT, Germany) from solution in THF with $20 \mathrm{mg} / \mathrm{ml}$ concentration at $1000 \mathrm{rot} / \mathrm{min}$ speed with acceleration of $500 \mathrm{rot} / \mathrm{s} 2$. DSC measurements were carried out with Mettler DSC 823E (Mettler Toledo, Switzerland) using $40 \mu \mathrm{l}$ Al pans.at a heating rate of $10 \mathrm{oC} / \mathrm{min}$ under argon atmosphere. Melting points and enthalpies of indium and zinc were used for temperature and heat capacity calibration.

Polarization Optical Microscopy (POM). The optical textures and thermal transition temperatures were evaluated with the help of a polarizing optical microscope equipped with a Mettler Toledo FP-82 HT hot stage and a microprocessor temperature control unit. The temperature of the tested samples was maintained with an accuracy of $0.1{ }^{\circ} \mathrm{C}$. Samples were placed on microscope slides (Fisherbrand, Fisher Scientific, USA) and covered with cover slips. The slides were used as received. The heating/cooling rate was $5 \circ \mathrm{C} / \mathrm{min}$.

GIWAXS experiments were performed on the BM26 beamline of ESRF (Grenoble, France) using the photon energy of $12 \mathrm{keV}$ (wavelength - $1.04 \AA$ ). The 2D data were collected at an incidence angle of $0.2^{\circ}$ using a FReLoN $2 \mathrm{k} C C D$ detector with sampletodetector distance of ca. $133 \mathrm{~mm}$. The modulus of the scattering vector $\mathrm{s}(|\mathrm{s}|=2 \sin \theta / \lambda$, where $\theta$ is the Bragg angle) was calibrated with 7 orders of silver behenate. The 1D reduction of the data and fitting was performed with home-made routines built in Igor Pro (Wavemetrics Ltd.). 
FTIR spectra were recorded with IFS $66 \mathrm{v} / \mathrm{s}$ (Bruker, Germany) (30 scans, resolution $1.0 \mathrm{~cm}$-1, wavelength range $400-4000$ $\mathrm{cm}-1$ ). Samples were prepared in the form of thin layers squeezed between two KBr optical glasses. Thin layers were obtained from THF solutions after solvent evaporation.

\section{Conclusions}

In the present work, we have investigated new complexes of triphenylene discotics, namely, 2,3,6,7,10,11 - hexakis(pentyloxy) triphenylene (H5T) and 2-(acryloyloxypropyloxy)- 3,6,7,10,11- pentapentyloxy-triphenylene (TPh-3A), with an electron acceptor, $\beta$ - (2,4,7-trinitro-9- fluorenylideneaminooxy) propionic acid (TNF-carb). One of the discotics is a well-known H5T, whereas the second one is a H5T- modified acrylic monomer- TPh-3A. In both cases, a new electron acceptor TNF -carb is used. Our studies by means of grazing-incidence X-ray diffraction and FTIR spectroscopy are focused on establishing the structure of the complexes and evaluating the impact of structural modification of the discotic constituents on the complex formation. Based on the results of synchrotron GIWAXS experiments, we found that constituent discotics crystallize in orthorhombic unit cells whereas complexation of H5T and TPh-3A with TNFcarb results in a double gyroid and hexagonal phases, respectively. Modelling of the double gyroid phase makes us supposing that the TNF-carb acceptor occupies the nodes of the double gyroid structure while the H5T molecules are located in the struts forming triple junctions at each node. For the hexagonal crystal of the TPh-3A /TNF-carb complex, the acceptor molecules are likely located in the interstices between the neighboring supramolecular columns of TPh-3A. It can be then concluded that even a small modification in the structure of H5T can result in a significant variation of the structure of its complex with TNF-carb. In particular, addition of a relatively small but asymmetric 2-(acryloyloxy-propyloxy) group on one of the alkyl arms of H5T makes dramatically changes the symmetry of the phase. The described impact of a small substituent on the final supramolecular structure can be accounted for by its $\mathrm{H}$-bonding with the carboxylic group of TNF-carb.

The molecular structures of the blends were explored by means of FTIR spectroscopy. A detailed FTIR spectra analysis illustrates fine changes in inter-molecular bonds. The initially dimerized acceptor molecules totally collapse in the complex structures whereas additional $\mathrm{H}$-bonds between the carboxylate group in TNF-carb and the ester group of TPh-3A contribute in the formation of TPh-3A/TNF-carb complex. At room temperature, the triphenylene - based compounds H5T and TPh-3A crystallize in orthorhombic unit cells. The complexes with TNF-carb reveal different structures from those of the pristine discotics. As shown with FTIR, the donoracceptor interaction binding the nitrogen atoms of nitro groups and electron-deficient carbon atoms in the aromatic cores as well oxygen atoms in the ether groups is the same in both complexes. Hydrogen bonds between the hydrogen atom in carboxylate group of TNF-carb and oxygen atom in the alkoxy-group in the discotic molecule participate in binding as well. However, the latter bond is less pronounced in TPh-3A containing system. At the same time, the ester group in TPh- 3A forms an additional $\mathrm{H}$-bond with carboxylate group in TNFcarb. The difference between molecular structures of the complexes may be a possible reason for the change in the phase structure types when instead of H5T TPh-3A molecules contribute in the complex formation. The conclusions section should come in this section at the end of the article, before the acknowledgements.

\section{Author Contributions}

Conceptualization, R.V.T and D.A.I.; methodology, G.N.B., A.S.M., G.A.S.; investigation, O.A.O., A.A.P., A.V.M. All authors have read and agreed to the published version of the manuscript.

\section{Conflicts of interest}

There are no conflicts to declare.

\section{Acknowledgements}

The work of the TIPS RAS was carried out within the State Program of TIPS RAS. The MSU team acknowledges financial support from the Ministry of Science and Higher Education of the Russian Federation within State Contract 075-15-2019- 1889.

\section{References}

1 B.R. Kaafarani, Chem.Mater., 2011, 23, 378

2 S. Chandrasekhar, B.K. Sadashiva, K.A. Suresh, Pramana, 1977, 9, 471; N. Boden and B. Movaghar, in Handbook of Liquid Crystals, 1998, 2B, 781; A.N. Cammidge, R.J. Bushby, in Handbook of Liquid Crystals, 1998, 2B, 693; S. Chandrasekhar, in Handbook of Liquid Crystals, 1998, 2B, 749

3 J.M. Wolska, D. Pociecha, J. Mieczkowski, E. Gorecka. Liq. Cryst., 2015, 43, 235; M. Vogrin, M. Vaupoti, M.M. Wojcik, J. Mieczkowski, K. Madrak, D. Pociecha, E. Gorecka Phys. Chem. Chem. Phys., 2014, 16, 16067; J-M. Suisse, H. Mori, H. Monobe, S. Kutsumizu, Y. Shimizu. Soft Matt., 2011, 7,

11086; O. Shimizu, K. Oikawa, K. Nakayama, D. Guillon, J. Mater.Chem. 2007, 17, 4223; T. Ichikawa, M. Yoshio, A. Hamasaki, T. Mukai, H. Ohno, T. Kato, J. Am. Chem. Soc., 2012, 134, 634

4 C. Destrade, M. Mondon, M.C. Malthete, J. Phys. Colloques 1979, 40, C3-17 - C3-21; N. Boden, R. J. Bushby, J. Clements, R. Luo, J. Mater. Chem. 1995, 5, 1741; P. S. Kumar, S. Kumar, and V. Lakshminarayanan, J. Phys. Chem. B. 2008, 112, 4865 5 T. Wöhrle, I. Wurzbach, J. Kirres, A. Kostidou, N. Kapernaum, J. Litterscheidt, J. C. Haenle, P. Staffeld, A. Baro, F. Giesselmann, S. Laschat. Chem. Rev. 2016, 116, 1139

6 B. Mu, Y. Zhao, X. Li, X. Quan, W. Tian. ACS Appl. Mater. Interfaces 2020, 12, 9637

7 H.R. Luss, D.L. Smith, Acta Crystallogr. Sect. B: Struct. Crystallogr. Cryst. Chem., 1972, 28, 884

8 L.K. Minacheva, V.S. Sergienko, S.B. Strashnova, O.V. Avramenko, O.V. Koval'chukova, O.A. Egorova, B.E. Zaitsev,

Crystallography Reports, 2005, 50, 72

9 Y.S. Bulyshev, I.M. Kashirskii, and V.V. Sinitskii, Phys. Status Solidi A, 1984, 82, 537 
10 L.A. Haverkate, M. Zbiri, M.R. Johnson, E. Carter, A. Kotlewski, S.J. Picken, F.M. Mulder, G.J. Kearley, J. Chem. Phys., 2014, 140, 014903

11 H. Ringsdorf, R. Wustefeld, E. Zerta, M. Ebert, J.H. Wendorf, Angew. Chem., Int. Ed. Engl., 1989, 28, 914; D. Markovitsi, H. Bengs, H. Ringsdorf J. Chem.Soc., Faraday Trans., 1992, 88, 1275; M. Ebert, G.G. Frick, C. Baehr, J.H. Wendorff, R. Wüstefeld, H. Ringsdorf. Liq.Cryst., 1992, 11, 293; K. Tao, T. Wu, D. Lu, R. Bai., H. Li, J. Mol. Liq. 2008, 142, 118; O.R. Lozman, J.G. Vinter. J. Chem. Soc., Perkin Trans., 2001, 2, 1446; N. Boden, N., R.J. Bushby, O.R. Lozman, Mol. Cryst. Liq. Cryst., 2004, 411, 345; 26. Y. Li, M.-G. Li, Y-J. Su, J-G Liu, Y-Ch Han, S-J. Zheng, J. Mol. Liq 2016, 224, 721; A.R. Yuvaraj, A. Renjith, S. Kumar, J. Mol. Liq., 2018, 272, 583

12 O. Kruglova, E. Mencles, Z. Yildirim, M. Wubbenhorst, F.M. Mulder, J.A. Stride., S.J Picken, G.J. Kearley. ChemPhysChem, $2007,8,1338$

13 L.A. Haverkate, M. Zbiri, M.R. Johnson, E. Carter, A. Kotlewski, S.J. Picken, F.M. Mulder, G.J. Kearley., J. Phys. Chem. B, 2012, 116, 13098

14 G.N. Bondarenko, S.A. Legkov, A.S. Merekalov, O.A. Otmakhova, R.V. Talroze. Russ J Phys Chem A, 2021 (submitted) 15 M Cotrait, P. Marsau, C. Destrade, J. Malthete, Journal de Physique Lettres, Edp sciences, 1979, 40, 519

16 T. Wang, D. Yan J. Luo, E. Zhou, O. Karthaus, H. Ringsdorf, Liq. Cryst., 1997, 23, 869

17 Y. Chen, M.D. Lingwood, M. Goswami, B.E. Kidd, J.J. Hernandez, M. Rosenthal, D.A. Ivanov, J. Perlich, H. Zhang, X. Zhu, M. Möller, L.A. Madsen, J. Phys. Chem. B, 2014, 118, 3207

18 J.J. Hernandez, H. Zhang, M. Rosenthal, M.D. Lingwood, M. Goswami, Y. Chen, X. Zhu, M. Möller, L. Madsen, D.A. Ivanov, Macromolecules, 2017, 50, 5392

19 A. Avgeropoulos, D. Moschovas, E.L. Thomas, N. Hadjichristidis, G. Zapsas, K. Ntetsikas, D.A. Ivanov, A.A. Piryazev, Nanomaterials, 2020, 10, 1497

20 H. Zhang, L. Li, M. Möller, X. Zhu, J.J.H. Rueda, M. Rosenthal, D.A. Ivanov, Adv. Mater., 2013, 25, 3543

21 R.I. Gearba, D.V. Anokhin, A.I. Bondar, W. Bras, M. Lehmann, D.A. Ivanov. Adv. Mater., 2017, 19, 815

22 R.I. Gearba, N. Dubreuil, D.V. Anokhin., Y.K. Godovsky, J-J. Ruan, A. Thierry, B. Lotz, D.A. Ivanov. Macromolecules, 2006, 39, 978

23 Molecular vibrations: The theory of infrared and Raman vibrational spectra. E. Bright Wilson, J.C. Decius, Paul C. Cross. New York a.o., McGr-Hill 1955, 394 pp.

24 K.N. Grafskaia, D.V. Anokhin, B.I. Zimka, I.A. Izdelieva, X. Zhu and D.A. Ivanov Chem. Commun. 2017, 53, 13217

25 N. Boden, R.C. Borner, R.J. Bushby, A.N. Cammidge, M.V. Jesudason. Liq. Cryst. 1993, 15, 851; R.C. Borner, R.J. Bushby, A.N. Cammidge, Liq. Cryst., 2006, 33, 1439

26 P. Schumacher, PhD Thesis, Mainz University, 1995

27 M. Möller, V. Tsukruk, J.H. Wendorf, H. Bengs, H. Ringsdorf, Liq. Cryst. 1992, 12, 17; M.S. Newman, H. Junjappa, J. Org. Chem., 1971, 36, 2606. 